\title{
Perencanaan Jaringan Air Minum Daerah Aliran Zona Prioritas Berdasarkan RISPAM Kabupaten Pidie
}

\author{
Geral Midyen ${ }^{1}$ Azmeri ${ }^{2}$ Amir Fauzi ${ }^{3}$ \\ ${ }^{1}$ Mahasiswa, Jurusan Teknik Sipil, Universitas Syiah Kuala, Banda Aceh 23111, Indonesia \\ ${ }^{2,3}$ Dosen, jurusan Teknik Sipil, Universitas Syiah Kuala, Banda Aceh 23111, Indonesia. \\ Email: geralmidyen11@gmail.com
}

\begin{abstract}
Pidie District has designed the master plan of drinking water supply system to evaluate the readiness of the drinking water supply system program in prioritized zones have not been fulfilled. Therefore, this study aimed to design a drinking water network model employing EPANET software to meet the water demand in the areas. The scope of this research included the projected population, water demand, dependable flow, and pipeline network modeling integrating three water treatment plants (WTPs), namely Keumala, Jabal Ghafur, and Garot. The population was projected for 20 years to examine the water demand in each WTP service. The results indicated that the production of Jabal Ghafur, Garot, and Keumala WTP should be increased by 130 liters/second, 70 liters/second, and 30 liters/second, respectively. The results of the drinking water network modeling suggested that the dimension of the distribution pipes in the three WTPs needs changing. They were 69, 65, and 36 pipes at the Keumala, Garot and Jabal Ghafur WTP services. The modeling result provides a service fulfilling the flow hydraulics for all of the WTP services.
\end{abstract}

Keyword: EPANET, priority zone, pipeline, water treatment plan.

\begin{abstract}
Abstrak
Kabupaten Pidie telah membuat Rencana Induk Sistem Penyediaan Air Minum (RISPAM) yang bertujuan untuk mengevaluasi kesiapan program SPAM pada zona-zona yang diprioritaskan yang belum terpenuhi. Penelitian ini bertujuan melakukan pemodelan jaringan air minum menggunakan software EPANET agar dapat memenuhi kebutuhan air. Penelitian ini meliputi proyeksi jumlah penduduk, kebutuhan air, debit andalan, dan pemodelan jaringan perpipaan dengan tiga Instalasi Pengolahan Air (IPA) yaitu Keumala, Jabal Ghafur, dan Garot. Proyeksi jumlah penduduk direncanakan selama 20 tahun untuk mengetahui kebutuhan air di tiap layanan IPA. Hasil penelitian diperlukan penambahan produksi IPA Jabal Ghafur sebesar 130 liter/detik, IPA Garot sebesar 70 liter/detik, dan IPA Keumala sebesar 30 liter/detik. Berdasarkan hasil pemodelan jaringan air minum diperlukan perubahan dimensi pipa distribusi pada layanan IPA Keumala sebanyak 69 pipa, IPA Garot sebanyak 65 pipa, dan layanan IPA Jabal Ghafur sebanyak 36 pipa. Hasil pemodelan memberikan pelayanan yang dapat memenuhi dalam hal hidrolika aliran untuk seluruh dari layanan.
\end{abstract}

Kata Kunci: EPANET, zona prioritas, jaringan pipa, water treatment plan.

\section{Pendahuluan}

Air baku sangat diperlukan untuk berbagai keperluan terutama air minum untuk rumah tangga, tempat umum, industri dan lain-lain. Kebutuhan air akan terus meningkat dari waktu ke waktu sejalan dengan lajunya pembangunan berbagai sektor dan bidang serta jumlah penduduk yang terus bertambah. Berdasarkan Peraturan Pemerintah Republik Indonesia[1] tentang pengembangan Sistem Penyediaan Air Minum (SPAM), SPAM merupakan tanggung jawab pemerintah daerah (pemerintah kabupaten/kota). Pemerintah daerah dalam melaksanakan penyediaan kebutuhan air minum dilaksanakan melalui instansi PDAM (Perusahaan Daerah Air Minum).

Pada tahun 2014 Kabupaten Pidie telah membuat Rencana Induk Pengembangan Sistem Penyediaan Air Minum[2] yang bertujuan untuk membantu BAPPEDA (Badan Perencanaan Pembangunan Daerah) dalam mengevaluasi kriteria kesiapan program pengembangan SPAM Kabupaten Pidie
Menurut Nihayati[3] pelanggan PDAM daerah Kabupaten Pidie mengeluh, terpaksa membeli air galon, kondisi ini diakibatkan karena sarana pelayanan air bersih Kabupaten Pidie belum mampu untuk memenuhi seluruh kebutuhan air bersih masyarakat. Berdasarkan permasalahan tersebut, maka penulisan ini bertujuan melakukan pemodelan jaringan air minum menggunakan software EPANET agar dapat memenuhi kebutuhan air di lokasi tersebut dengan proyeksi 20 tahun dari tahun 2018-2037 perencanaan.

Lingkup penelitian ini adalah proyeksi jumlah penduduk, kebutuhan air, kehilangan air, analisis kebutuhan air maksimum harian dan jam puncak, analisa debit andalan dan pemodelan jaringan perpipaan pada tiga IPA yaitu Keumala, Jabal Ghafur, dan Garot.

\section{Tinjauan Pustaka}

\subsection{Proyeksi Jumlah Penduduk}

Menurut Tuames[4] dalam merencanakan kebutuhan air bersih, proyeksi jumlah penduduk 
merupakan faktor penting dimana pembangunan diruntukan kepada kepentingan penduduk. Proyeksi jumlah penduduk dilakukan dengan 3 metode yaitu metode Aritmatik, Geometrik, dan Eksponensial dengan menggunakan rumus dibawah ini :

1. Metode Aritmatik

$$
\begin{aligned}
& K_{a}=\frac{P_{2}-P_{1}}{T_{2}-T_{1}} \ldots \ldots \ldots \ldots \ldots \ldots \ldots \ldots \\
& P_{n}=P_{o}+[k a(T n-T o)]
\end{aligned}
$$

2. Metode Geometrik

$$
P_{n}=P_{o}(1+\mathrm{r})^{n}
$$

3. Metode Eksponensial

$$
P_{n}=P_{o} \times e^{n \times r}
$$

Keterangan :

$P_{n}=$ jumlah penduduk pada tahun ke $\mathrm{n}$ (jiwa);

$P_{o}=$ jumlah penduduk pada tahun dasar (jiwa);

$T_{n}=$ tahun ke n (tahun);

$T_{o}=$ tahun dasar (tahun);

$K_{a}=$ rata-rata pertambahan penduduk (jiwa);

$P_{1}=$ jumlah penduduk yang diketahui pada tahun ke I (jiwa);

$P_{2}=$ jumlah penduduk yang diketahui pada tahun terakhir (jiwa);

$T_{1}=$ tahun ke I yang diketahui (tahun);

$T_{2}=$ tahun ke II yang diketahui (tahun);

$\mathrm{e}=$ bilangan eksponensial $=2,71828$;

$\mathrm{r}=$ laju pertumbuhan penduduk (\%); dan

$\mathrm{n}=$ jumlah interval tahun (tahun).

Pemilihan metode proyeksi jumlah penduduk berdasarkan cara pengujian statistik yakni berdasarkan standar deviasi terkecil dengan menggunakan rumus dibawah ini :

$$
\mathrm{s}=\sqrt{\frac{\sum(y i-y m e a n)^{2}}{n}}
$$

Keterangan :

$$
\begin{array}{ll}
\text { yi } & =\text { jumlah penduduk proyeksi (jiwa); } \\
\text { ymean } & =\text { rata-rata jumlah penduduk; dan } \\
\text { S } & =\text { standar deviasi }
\end{array}
$$

\subsection{Kebutuhan Air}

Menurut Wijanarko[5] kebutuhan air adalah jumlah air yang dibutuhkan untuk keperluan rumah tangga, industri, pengelontoran kota dan lainya. Kebutuhan air domestik yaitu kebutuhan air yang digunakan pada tempat-tempat hunian pribadi untuk memenuhi keperluan sehari - hari seperti, memasak, minum, mencuci dan keperluan rumah tangga lainya. Kebutuhan air non-domestik adalah sarana dan prasarana berupa kepentingan social/umum seperti untuk pendidikan, tempat ibadah, kesehatan, industri dan dll. Rumus dalam mencari kebutuhan air domestik dan air non-domestik dapat dihitung dengan menggunakan rumus Naway[6] :

$\mathrm{Q}(\mathrm{DMI})=\mathrm{P}_{\mathrm{n}} \times \mathrm{qSR}$

$\mathrm{Q}(\mathrm{N}-\mathrm{DMI})=\mathrm{Q}(\mathrm{DMI}) \mathrm{x}$ konsumsi unit non-domestik Air . .7)

Keterangan :

\begin{tabular}{|c|c|c|c|c|c|c|}
\hline \multirow{3}{*}{ No. } & \multirow{3}{*}{ URA I A N } & \multicolumn{5}{|c|}{ KATEGORI KOTA BERDASARKAN JUMLAH PENDUDUK (JIWA) } \\
\hline & & $>1.000 .000$ & $\begin{array}{c}500.000 \mathrm{~s} / \mathrm{d} \\
1,000,000\end{array}$ & $\begin{array}{c}100.000 \mathrm{~s} / \mathrm{d} \\
500\end{array}$ & $\begin{array}{c}20.000 \mathrm{~s} / \mathrm{d} \\
100\end{array}$ & $<20.000$ \\
\hline & & METRO & BESAR & SEDANG & KECIL & DESA \\
\hline 1 & $\begin{array}{l}\text { Konsumsi unit sambungan } \\
\text { rumah (SR) liter/orang/hari }\end{array}$ & 190 & 170 & 150 & 100 & 80 \\
\hline 2 & $\begin{array}{l}\text { Konsumsi unit Hidran Umum } \\
\text { (HU) liter/orang/hari }\end{array}$ & 30 & 30 & 30 & 30 & 30 \\
\hline 3 & $\begin{array}{l}\text { Konsumsi unit Non Domestik } \\
(\%)\end{array}$ & 20-30 & $20-30$ & $20-30$ & $20-30$ & $20-30$ \\
\hline 4 & Kehilangan air $(\%)$ & $20-30$ & $20-30$ & $20-30$ & $20-30$ & 20 \\
\hline 5 & Faktor maximum day & 1,1 & 1,1 & 1,1 & 1,1 & 1,1 \\
\hline 6 & Faktor Peak-Hour & 1,5 & 1,5 & 1,5 & 1,5 & 1,5 \\
\hline 7 & Jumlah jiwa per SR & 5 & 5 & 6 & 6 & 10 \\
\hline 8 & Jumlah jiwa per $\mathrm{HU}$ & 100 & 100 & 100 & $100-200$ & 200 \\
\hline 9 & $\begin{array}{l}\text { Sisa tekan di jaringan } \\
\text { distribusi(mka) }\end{array}$ & 10 & 10 & 10 & 10 & 10 \\
\hline 10 & Jam Operasi & 24 & 24 & 24 & 24 & 24 \\
\hline 11 & $\begin{array}{l}\text { Volume reservoir (\%) (maks } \\
\text { day demand) }\end{array}$ & 20 & 20 & 20 & 20 & 20 \\
\hline 12 & SR:HU & $\begin{array}{l}50: 50 \mathrm{~s} / \mathrm{d} \\
70: 30\end{array}$ & $\begin{array}{c}50: 50 \mathrm{~s} / \mathrm{d} \\
80: 20\end{array}$ & 80:20:00 & 70:30:00 & 70:30:00 \\
\hline 13 & Cakupan Pelayanan (\%) & **) 90 & **) 90 & **) 90 & $* *) 90$ & $* * *) 70$ \\
\hline
\end{tabular}

$\mathrm{Q}$ (DMI) = kebutuhan air untuk kebutuhan domestik (liter/hari);

$\mathrm{Q}(\mathrm{N}-\mathrm{DMI})=$ kebutuhan air non-domestik (liter/hari); dan

qSR = komsumsi unit sambungan rumah (liter/orang/hari).

Tabel 1 Kriteria perencanaan air bersih domestik

Sumber : NSPM Kimpraswil[7].

\subsection{Kehilangan Air}

Menurut Maukari[8] masalah kehilangan air (unaccounted for water) masih merupakan salah satu masalah yang sangat besar bagi pengelola air minum di Indonesia. Rumus dalam menghitung kehilangan air dapat dihitung dengan rumus berikut :

$\mathrm{Qka}=(\mathrm{QDMI}+\mathrm{QN}-\mathrm{DMI}) \mathrm{x} \mathrm{Ka}$.

Qrh $=$ QDMI + QN-DMI + Qka

Keterangan :

Qka = Kehilangan air (liter/hari);

Qrh = Kebutuhan air harian (liter/hari); dan

$\mathrm{Ka}=$ Faktor Kehilangan air $(\%)$.

\subsection{Harian Maksimum dan Jam Puncak}

Menurut Direktorat Jenderal Cipta Karya[9] jam puncak dan harian maksimum adalah dua istilah yang saling berkaitan dalam pola pemakaian air. Variasi perubahan pemakaian air oleh konsumen dari waktu secara periodik disebut fluktuasi.

1. Kebutuhan air harian maksimal

Kebutuhan air harian maksimal adalah kebutuhan air pada hari-hari tertentu seperti pada hari libur, hari lebaran dan lain-lain. Kebutuhan air harian maksimal dapat dihitung dengan menggunakan rumus.

$Q h m=f(\max d a y) x$ Qrh

2. Kebutuhan air jam puncak

Kebutuhan air jam puncak adalah kebutuhan air pada jam-jam tertentu seperti pada pagi hari dan sore saat orang-orang mandi, saat sholat magrib, dan lain-lain. Kebutuhan air jam puncak dapat dihitung dengan menggunakan rumus.

Qjm $=f($ peak hour $) \times$ Qrh

Keterangan :

$f_{(\text {peak hour })}=$ faktor jam puncak;

$f_{\text {(max day })}=$ faktor harian maksimum;

$Q_{h m} \quad=$ kebutuhan harian maksimum (liter/hari); dan 


\section{$Q_{j m} \quad=$ kebutuhan air jam puncak (liter/hari). \\ 2.6 Kriteria Perencanaan Pipa Transmisi dan Pipa Distribusi}

Menurut [10] pipa transmisi berfungsi untuk mengalirkan air dari sumber ke reservoir dan pengolahan air, maupun dari reservoir menuju reservoir lainya. Tekanan air diukur dari permukaan tanah, sedangkan pada sambungan pelanggan diukur pada sambungan pipa pelayanan.

\subsection{Persamaan Bernoulli}

Menurut Badan Standarisasi Nasional[11] prinsip Bernoulli adalah sebuah istilah di dalam mekanika fluida yang menyatakan bahwa pada suatu aliran fluida, peningkatan pada kecepatan fluida akan menimbulkan penurunan tekanan pada aliran tersebut. Konstanta $\mathrm{C}$ adalah tinggi energi total, yang merupakan jumlah dari tinggi elevasi, tinggi tekanan dan tinggi kecepatan, yang berbeda dari garis arus yang satu ke garis arus yang lain. Persamaan Bernoulli dapat digunakan untuk menentukan garis tekanan dan tenaga.

$$
\begin{aligned}
& z_{1}+\frac{p_{1}}{\Upsilon_{1}}+\frac{v_{1}^{2}}{2 g}=z_{2}+\frac{p_{2}}{\Upsilon_{2}}+\frac{v_{2}^{2}}{2 g}+h f \\
& h f=\frac{10,666 \times Q^{1,85}}{C^{1,85} \times d^{4,85}}
\end{aligned}
$$

Keterangan :

$$
\begin{array}{ll}
\mathrm{Z} & =\text { elevasi pipa }(\mathrm{m}) ; \\
\mathrm{P} & =\text { tekanan }(\mathrm{m}) ; \\
\mathrm{V} & =\text { kecepatan aliran }\left(\mathrm{m}^{3} / \mathrm{s}\right) ; \\
\mathrm{Y} & =\text { berat jenis }\left(\mathrm{N} / \mathrm{m}^{3}\right) ; \\
\mathrm{h}_{\mathrm{f}} & =\text { kehilangan energi }(\mathrm{m}) ; \\
Z_{1}, Z_{2} & =\text { tinggi elevasi di titik } 1,2(\mathrm{~m}) ; \\
\frac{p_{1}}{\Upsilon_{1}}, \frac{p_{2}}{\Upsilon_{2}} & =\text { tinggi tekanan di titik } 1,2(\mathrm{~m}) ; \\
\frac{v_{1}^{2}}{2 g}, \frac{v_{2}^{2}}{2 g} & =\text { tinggi kecepatan di titik } 1,2(\mathrm{~m} / \mathrm{s}) ; \\
\mathrm{L} & =\text { panjang pipa }(\mathrm{m}) ; \\
\mathrm{d} & =\text { diameter pipa }(\mathrm{m}) ; \\
\mathrm{g} & =\text { percepatan gravitasi }\left(\mathrm{m} / \mathrm{s}^{2}\right) ; \text { dan } \\
C & =\text { koefisien gesekan Hazen William. }
\end{array}
$$

\subsection{Debit Andalan}

Menurut [12] debit andalan merupakan debit yang diandalkan untuk suatu probabilitas tertentu yang berbeda-beda. Untuk keperluan air minum digunakan probabilitas 90\% sampai dengan 95\%. Debit andalan dapat diperoleh dari pengolahan data curah hujan dengan menggunakan perhitungan Metode F. J. Mock dengan mengurutkan debit rata-rata bulanan dari urutan besar keurutan kecil. Nomor urut data yang merupakan debit andalan Metode F. J. Mock dapat dihitung dengan mengunakan rumus:

$$
\operatorname{Pr}=\frac{m}{n+1} \times 100 \%
$$

Keterangan :

$\operatorname{Pr}=$ probabilitas $(\%)$

$\mathrm{n}=$ jumlah tahun data; dan

$\mathrm{m}=$ nomor urut data setelah diurut dari nilai besar kenilai yang kecil.

\subsection{Aplikasi EPANET 2.0 Dalam Sistem PenyediaanAir Bersih}

Menurut Tambun[11] EPANET adalah program komputer yang menggambarkan simulasi hidrolis dan kecenderungan kualitas air yang mengalir di dalam jaringan pipa. Pemograman EPANET jaringan itu terdiri atas pipa, node, pompa, katub dan tangki air atau reservoir.

\section{Metode penelitian}

\subsection{Objek Penelitian}

Penelitian ini dilakukan pada jaringan Instalasi Pengolahan Air (IPA) Keumala, IPA Garot, dan IPA Jabal Ghafur di Kabupaten Pidie yang mengaliri air ke empat kecamatan zona prioritas yaitu Kota Sigli, Kecamatan Pidie, Indra Jaya, dan Keumala.

\subsection{Pengumpulan Data}

Data primer bermula dengan melakukan tanya jawab dengan pihak petugas IPA Garot, IPA Keumala, IPA Jabal Ghafur, dan pihak PDAM Tirta Mon Krueng Baro mengenai informasi jaringan pipa air minum dan pertambahan jaringan pipa selanjutnya melakukan pengamatan langsung di lapangan mengenai. Data sekunder adalah data yang diperoleh dari instansiinstansi terkait yang terdiri dari peta DAS dan subDAS, data jumlah penduduk, data curah hujan, peta eksisting jaringan IPA, laporan pelanggan aktif SR, data DAS Krueng Baro, kondisi Eksisisting IPA, data Klimatologi.

\subsection{Teknik Analisis}

\subsubsection{Proyeksi jumlah penduduk}

Dari data jumlah penduduk yang didapatkan dari badan statistik Kabupaten Pidie dari tahun 2009 - 2017 maka akan dilakukan proyeksi jumlah penduduk dengan menggunakan Metode Aritmatik, Geometrik, dan Eksponensial dengan menggunakan persamaan (1) - (4) untuk mendapatkan nilai proyeksi jumlah penduduk. Pemilihan metode proyeksi jumlah penduduk akan dipilih berdasarkan perhitungan standar deviasi terkecil dengan menggunakan persamaan (5).

\subsubsection{Kebutuhan air}

Perhitungan dimulai setelah didapatkan proyeksi jumlah penduduk akan diketahui kota berdasarkan jumlah penduduk yang menempati Kecamatan Indra Jaya, Keumala, Pidie, dan Sigli seperti tertera pada Tabel 1 Kategori kota mempergaruhi dalam penentuan komsumsi unit sambungan rumah (SR), kehilangan air, jumlah jiwa per SR. Kebutuhan air domestik menggunakan persamaan (6), dikarenakan data pemakaian air untuk kebutuhan non-domestik tidak tersedia maka akan dilakukan perhitungan dengan persamaan (7). Penentuan tingkat layanan dan penduduk terlayani dengan menggunakan asumsi RISPAM yaitu 
pada akhir tahun perencanaan akan didapatkan 100\% tingkat layanan dan $100 \%$ penduduk terlayani.

\subsubsection{Kehilangan air}

Perhitungan dimulai setelah didapatkan kebutuhan air domestik dan non-domestik, dalam perhitungan kehilangan air menggunakan persamaan (8) digunakan faktor kehilangan air berdasarkan Tabel 2.1. Setelah didapatkan kehilangan air maka kebutuhan air harian dengan menggunakan persamaan (9). Perhitungan kebutuhan air harian maksimum dan jam puncak digunakan dalam perencanaan untuk mendapatkan kebutuhan dengan menggunakan persamaan (10) - (11).

\subsubsection{Perhitungan debit andalan}

Perhitungan besarnya ketersediaan air atau debit andalan pada sungai Krueng Baro dimulai dengan melakukan perhitungan Evapotranspirasi Potensial $\left(E T_{0}\right)$ dengan metode Penman Modifikasi dengan menggunakan data klimatologi dari tahun 2012 hingga 2017. Setelah didapatkan $E T_{0}$ akan dilanjutkan dengan menggunakan metode F. J. Mock untuk mencari debit andalan dikarenakan banyak koefisien yang dapat diubah sesuai dengan kondisi DAS. Debit yang telah didapatkan akan diurutkan untuk mendapatkan probabilitias $\mathrm{Q}_{90}$ menggunakan persamaan (14).

\subsubsection{Pemodelan Jaringan Perpipaan dengan Software EPANET 2.0}

Pemodelan dimulai setelah diketahui kebutuhan air jam puncak (Qjm) pada setiap kecamatan yang berada pada zona prioritas dan wilayah pelayanan pada setiap desa yang berada pada setiap zona prioritas dengan melakukan digitasi dengan menggunakan Google Earth. Data yang menjadi parameter dalam pemodelan EPANET 2.0 antara lain peta eksisting, elevasi tiap node, panjang pipa, diameter pipa, koefisien kekasaran pipa, dan debit andalan sebagai data untuk mengetahui seberapa besar air yang tersedia pada sungai Krueng Baro. Proses running model jaringan dikembangkan menggunakan software EPANET 2.0.

\section{Hasil dan Pembahasan}

\subsection{Proyeksi Jumlah Penduduk}

Langkah awal dalam perhitungan proyeksi jumlah penduduk dengan melakukan perhitungan $K_{a}$ dan (r) dengan menggunakan data sekunder dari tahun 2009 2017. Penentuan metode proyeksi penduduk berdasarkan standar deviasi terkecil yang didapat dari ketiga metode proyeksi yang dapat dilihat pada Tabel 2 Tabel 2 Rekapitulasi standar deviasi

\begin{tabular}{|c|c|c|c|c|}
\hline No & Kecamatan & Metode & Nilai & Standar De viasi \\
\hline \multirow{3}{*}{1} & \multirow{3}{*}{ Indra Jaya } & Aritmatik & 974 & \multirow{3}{*}{ Aritmatik } \\
\hline & & Geometrik & 975 & \\
\hline & & Eksponensial & 982 & \\
\hline \multirow{3}{*}{2} & \multirow{3}{*}{ Keumala } & Aritmatik & 423 & \multirow{3}{*}{ Aritmatik } \\
\hline & & Geometrik & 424 & \\
\hline & & Eksponensial & 427 & \\
\hline \multirow{3}{*}{3} & \multirow{3}{*}{ Pidie } & Aritmatik & 1912 & \multirow{3}{*}{ Aritmatik } \\
\hline & & Geometrik & 1914 & \\
\hline & & Eksponensial & 1930 & \\
\hline \multirow{3}{*}{4} & \multirow{3}{*}{ Sigli } & Aritmatik & 921 & \multirow{3}{*}{ Aritmatik } \\
\hline & & Geometrik & 925 & \\
\hline & & Eksponensial & 934 & \\
\hline
\end{tabular}

Berdasarkan hasil standar deviasi pada setiap kecamatan dan grafik visual tiga metode proyeksi dapat dilihat bahwa metode Aritmatik digunakan dalam proyeksi jumlah penduduk 20 tahun perencanaan. Rekapitulasi proyeksi jumlah penduduk dapat dilihat pada Tabel 3

Tabel 3 Rekapitulasi proyeksi jumlah penduduk

\begin{tabular}{cccccccc}
\hline & & \multirow{2}{*}{$\begin{array}{c}\text { Jumlah } \\
\text { NO Kecamatan }\end{array}$} & \multicolumn{5}{c}{ Proyeksi Jumlah Penduduk (Jiwa) } \\
\cline { 4 - 8 } & & $\begin{array}{c}5 \\
\text { Penduduk }\end{array}$ & & Tahun 2017 & \multicolumn{5}{c}{ Tahun } \\
\cline { 3 - 8 } & & $\mathbf{2 0 1 8}$ & $\mathbf{2 0 2 3}$ & $\mathbf{2 0 2 8}$ & $\mathbf{2 0 3 3}$ & $\mathbf{2 0 3 7}$ \\
\hline 1 & Indra Jaya & 23.638 & 24.015 & 25.899 & 27.784 & 29.668 & 31.176 \\
\hline 2 & Keumala & 10.161 & 10.325 & 11.144 & 11.962 & 12.781 & 13.436 \\
\hline 3 & Pidie & 45.431 & 46.171 & 49.870 & 53.570 & 57.269 & 60.229 \\
\hline 4 & Sigli & 21.485 & 21.841 & 23.622 & 25.402 & 27.183 & 28.608 \\
\hline
\end{tabular}

\subsection{Kebutuhan Air Minum}

Untuk menghitung kebutuhan air dilakukan perhitungan untuk menghitung tingkat layanan dan penduduk terlayani dengan asumsi RISPAM pada akhir tahun perencanaan akan didapatkan $100 \%$ tingkat layanan dan penduduk terlayani. Kebutuhan domestik (QDMI) melalui persamaan (6). kebutuhan nondomestik (QN-DMI) didapatkan melalui persamaan (7). Kehilangan air total (Qtot) didapatkan melalui pertambahan QDMI ditambah QN-DMI, kehilangan air (Qka) didapatkan melalui persamaan (8). Kebutuhan air harian maksimum (Qhm) dan kebutuhan air jam puncak (Qjm) didapatkan melalui persamaan (10)-(11). Perhitungan kebutuhan air Kecamatan Indra Jaya dapat dilihat pada Tabel 4

Tabel 4 Perhitungan Kebutuhan Air Kecamatan Indra

\begin{tabular}{|c|c|c|c|c|c|c|c|}
\hline \multirow{2}{*}{ No } & \multirow{2}{*}{ Uraian } & \multirow{2}{*}{ Satuan } & \multicolumn{5}{|c|}{ Tahun } \\
\hline & & & 2018 & 2023 & 2028 & 2033 & 2037 \\
\hline A & Kependudukan & & & & & & \\
\hline 1 & Jumlah Penduduk Total & Jiwa & 24.015 & 25.899 & 27.784 & 29.668 & 31.176 \\
\hline 2 & Tingkat Pelayanan & $\%$ & 5,52 & 29,14 & 52,76 & 76,38 & 100,00 \\
\hline 3 & Penduduk Terlayani & jiwa & 1.284 & 7.547 & 14.659 & 22.660 & 31.176 \\
\hline 4 & Jumlah Penduduk Per SR & jiwa & 6,00 & 6,00 & 6,00 & 6,00 & 6,00 \\
\hline B & Kebutuhan Domestik (QDMI) & & & & & & \\
\hline 1 & Jumlah SR & Unit & 214 & 1.258 & 2.443 & 3.777 & 5.196 \\
\hline 2 & Pemakaian per orang & liter/orang/hari & 100 & 100 & 100 & 100 & 100 \\
\hline 3 & Kebutuhan Air SR & m3/hari & 128 & 755 & 1.466 & 2.266 & 3.118 \\
\hline 4 & Kebutuhan Domestik & liter/dettik & 1,49 & 8,73 & 16,97 & 26,23 & 36,08 \\
\hline \multirow[t]{4}{*}{$\mathrm{C}$} & Kebutuhan non domestik (QN-DMI & & & & & & \\
\hline & $25 \%$ dari kebutuhan Domestik & $\%$ & 25 & 25 & 25 & 25 & 25 \\
\hline & Kebutuhan non domestik & m3/hari & 32,10 & 188,67 & 366,46 & 566,51 & 779,39 \\
\hline & & liter/detik & 0,37 & 2,18 & 4,24 & 6,56 & 9,02 \\
\hline D & Kebutuhan Air Total (Qtot) & liter/detik & 1,86 & 10,92 & 21,21 & 32,78 & 45,10 \\
\hline \multirow[t]{3}{*}{ E } & Kehilangan air (Qka) & & & & & & \\
\hline & $25 \%$ Kehilangan air & $\%$ & 25 & 25 & 25 & 25 & 25 \\
\hline & Jumlah kehilangan air & liter/detik & 0,46 & 2,73 & 5,30 & 8,20 & 11,28 \\
\hline $\mathrm{F}$ & Kebutuhan air harian (Qrh) & liter/detik & 2,32 & 13,65 & 26,51 & 40,98 & 56,38 \\
\hline \multirow[t]{3}{*}{$\mathrm{G}$} & Kebutuhan air maksimum $(\mathrm{Qhm})$ & & & & & & \\
\hline & Faktor koefisien & & 1,10 & 1,10 & 1,10 & 1,10 & 1,10 \\
\hline & Kebutuhan air Harian Maksimum & liter/detik & 2,55 & 15,01 & 29,16 & 45,08 & 62,02 \\
\hline \multirow[t]{3}{*}{$\mathrm{H}$} & Ke butuhan Jam Puncak (Qjm) & & & & & & \\
\hline & Faktor koefisien & & 1,50 & 1,50 & 1,50 & 1,50 & 1,50 \\
\hline & Kebutuhan Air Jam Puncak & liter/detik & 3,48 & 20,47 & 39,76 & 61,47 & 84,57 \\
\hline
\end{tabular}

Berdasarkan kriteria pipa distribusi dalam mendesain kebutuhan digunakan kebutuhan air jam puncak sebagai dasar kebutuhan. Berdasarkan hasil rekapitulasi didapatkan bahwa kebutuhan tertinggi 
terjadi pada Kecamatan Pidie sebesar 163,38 liter/detik dan terkecil pada Kecamatan Keumala sebesar 27,99 liter/detik

Tabel 5 Rekapitulasi Kebutuhan air

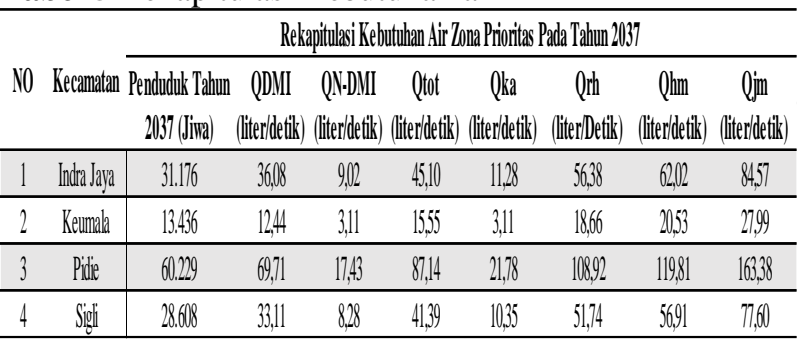

\subsection{Debit Andalan}

Langkah awal dalam menghitung debit andalan dengan menentukan luasan Cathment area yang dapat dilihat pada Tabel 6 Perhitungan Evapotranspirasi Potensial dengan menggunakan Metode Penman Modifkasi dapat dilihat hasil dengan menggunakan data Klimatologi dari tahun 2012 - 2017 pada Tabel 7.

Tabel 6 Rekapitulasi SubDAS dan Cathment Area

\begin{tabular}{ccccc}
\hline \multirow{2}{*}{ No } & Intalasi & Catchment Area & \multicolumn{2}{c}{ Stasiun Pengamat } \\
\cline { 4 - 5 } & Pengolahan Air & $\left(\mathbf{m}^{2}\right)$ & Hujan & Klimatologi \\
\hline 1 & Keumala & $152.025 .791,30$ & Kota Bakti & Kota Bakti \\
\hline 2 & Jabal Ghafur & $229.208 .871,04$ & Kota Bakti & Kota Bakti \\
\hline 3 & Garot & $239.417 .450,55$ & Kota Bakti & Kota Bakti \\
\hline
\end{tabular}

Tabel 7 Rekapitulasi evapotransipirasi potensial

\begin{tabular}{|c|c|c|c|c|c|c|c|c|c|c|c|}
\hline \multicolumn{12}{|c|}{ Erapotranspirnsi Potensial (ETO) } \\
\hline \multirow{2}{*}{ Parameter Satuan } & \multicolumn{11}{|c|}{ Bulan } \\
\hline & Jan & Mar & Apr & Mei & Jun & Jul & Agt & Sep & $0 \mathrm{kt}$ & Nor & Des \\
\hline mmlhari & 4,31 & 4,00 & 3,86 & 3,62 & 3,51 & 3,48 & 4,06 & 4,10 & 4,33 & 3,78 & 3,5 \\
\hline Eto & $120,05120.55$ & 142,48 & 115,67 & 11232 & 105,16 & 107,82 & 126,01 & 123,02 & 134,13 & 11338 & 107,07 \\
\hline
\end{tabular}

Setelah didapatkan Evapotranspirasi Potensial dapat dilanjutkan dengan menghitung debit andalan pada tiap IPA yaitu IPA Keumala, Jabal Ghafur, dan Garot dengan menggunakan metode F. J. Mock dan dilakukan probabilitas $90 \%$ yang dapat dilihat rekapitulasi pada Tabel 8

Tabel 8 Rekapitulasi debit andalan

$\mathrm{N} 0$

DebitAndan (m/detik)

Pengolahan Air Jan Feb Mar Apr Mei Juni Juli Agus Sept 0kt Nor Des

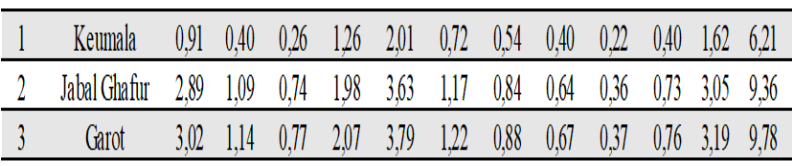

Berdasarkan perhitungan debit andalan, debit tertinggi terjadi pada bulan Desember pada IPA Garot sebesar 9,78 $\mathrm{m}^{3} /$ detik, dan debit andalan terendah pada bulan September pada IPA Keumala sebesar $0,22 \mathrm{~m}^{3} /$ detik.

\subsection{Simulasi jaringan air minum dengan program EPANET 2.0}

Simulasi EPANET zona prioritas meliputi 3 Instalasi Pengolahan Air (IPA) yaitu IPA Keumala, IPA Garot, dan IPA Jabal Ghafur dan wilayah pelayanan sesuai dengan RISPAM Kabupaten Pidie. Penentuan persentase pelayanan berdasarkan digitasi Google Earth. Wilayah pelayanan jaringan air minum dapat dilihat pada Tabel 9

Tabel 9 Wilayah Pelayanan jaringan air minum

\begin{tabular}{|c|c|c|c|c|}
\hline \multirow{2}{*}{ No } & \multirow{2}{*}{$\begin{array}{c}\text { Sumber Air } \\
\text { Baku }\end{array}$} & \multirow{2}{*}{$\begin{array}{c}\text { Instalasi } \\
\text { Pengolahan Air }\end{array}$} & \multicolumn{2}{|c|}{ Wilayah Pelayanan } \\
\hline & & & Kecamatan & Pelayanan (\%) \\
\hline \multirow{3}{*}{1} & Sungai Krueng & \multirow{3}{*}{ IPA Keumala } & Kec. Keumala & 100 \\
\hline & $\begin{array}{c}\text { Baro Desa Pako - } \\
\text { Keumala }\end{array}$ & & Kec. Pidie & 20,14 \\
\hline & Kecamatan & & Kota Sigli & 57,84 \\
\hline \multirow[b]{2}{*}{2} & Sungai Krueng & \multirow[b]{2}{*}{ IPA Garot } & Kec. Pidie & 46,48 \\
\hline & $\begin{array}{c}\text { Baro } \\
\text { Lampeunteut- }\end{array}$ & & Kota Sigli & 14,16 \\
\hline \multirow{3}{*}{3} & Box Primer & & Kec. Indra & 100 \\
\hline & Irigasi Keumala & IPA Jabal Ghafur & Kec. Pidie & 33,58 \\
\hline & Kec. Keumala & & Kota Sigli & 28,00 \\
\hline
\end{tabular}

\subsubsection{Perencanaan desain kebutuhan jaringan}

Produksi IPA diperlukan untuk mengetahui kapasitas IPA dalam memproduksi kebutuhan air RISPAM telah menyajikan data kontruksi, produksi dan trasmnisi IPA pada zona priortias yang dapat dilihat pada Tabel 10.

Tabel 10 Data kontruksi, produksi, dan tramsmisi IPA

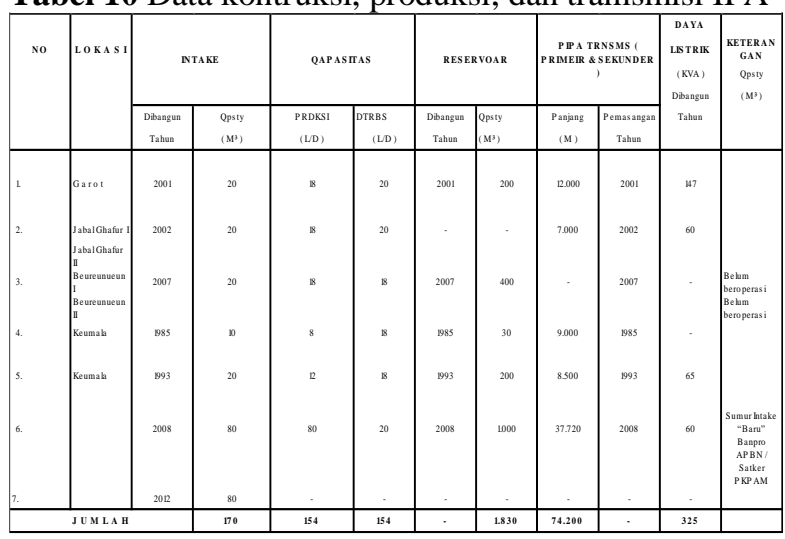

Berdasarkan hasil pada proyeksi jumlah penduduk telah didapatkan kebutuhan pada setiap kecamatan dan wilayah pelayanan dan diubah dalam kebutuhan tiap IPA dengan hasil pada Tabel 11 Berdasarkan kebutuhan pada tahun akhir perencanaan perlu dilakukan penambahan produksi IPA untuk dapat memproduksi seluruh kebutuhan pada zona prioritas yang dapat dilihat pada Tabel 12 IPA Keumala penambahan produksi sebesar 30 liter/detik, IPA Garot 70 liter/detik dan IPA Jabal Ghafur sebesar 130 liter/detik. 
Tabel 11 Rekapitulasi data perencanaan jaringan air minum

\begin{tabular}{cccccc}
\hline No & $\begin{array}{c}\text { Instalasi } \\
\text { Pengolahan Air }\end{array}$ & $\begin{array}{c}\text { Debit Andalan } \\
\text { (liter/detik) }\end{array}$ & $\begin{array}{c}\text { Kebutuhan pada } \\
\text { Tahun 2037 } \\
\text { (liter/detik) }\end{array}$ & $\begin{array}{c}\text { Maintenance } \\
\text { Flow 10\% } \\
\text { (liter/detik) }\end{array}$ & $\begin{array}{c}\text { Surplus/Defisit } \\
\text { (liter/detik) }\end{array}$ \\
\hline 1 & IPA Keumala & 1754,16 & 105,78 & 175,42 & 1472,97 \\
\hline 2 & IPA Garot & 2762,54 & 86,92 & 276,25 & 2399,36 \\
\hline 3 & IPA Jabal Ghafur & 2644,74 & 161,16 & 264,47 & 2219,11 \\
\hline
\end{tabular}

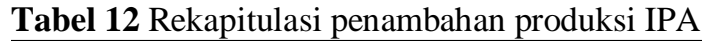

\begin{tabular}{ccccc}
\hline No & $\begin{array}{c}\text { Instalasi } \\
\text { Pengolahan Air }\end{array}$ & Produksi (liter/detik) & $\begin{array}{c}\text { Kebutuhan } \\
\text { (liter/detik) }\end{array}$ & $\begin{array}{c}\text { Penambahan } \\
\text { Produksi IPA } \\
\text { (liter/detik) }\end{array}$ \\
\hline 1 & IPA Keumala & 80 & 105,78 & 30 \\
\hline 2 & IPA Garot & 18 & 86,92 & 70 \\
\hline 3 & IPA Jabal Ghafur & 36 & 161,16 & 130 \\
\hline
\end{tabular}

\subsubsection{Simulasi pemodelan pemograman EPANET}

Pemograman EPANET terdapat dua kategori yaitu Link ID yang terdiri dari pipa dan Node ID yang terdiri dari junctions, pompa, tangki, dan reservoa. Hasil dari Link ID yang merupakan pipa yaitu kecepatan aliran (meter/detik) dan kehilangan energi (meter $/ \mathrm{km}$ ). Program EPANET 2.0 dapat menampilkan hasil running dalam bentuk Link ID yang terdiri dari panjang pipa, diameter pipa, kekasaran pipa, debit kecepatan aliran, dan kehilangan energi seperti yang dapat dilihat pada Tabel 13 Link ID eksisting pada IPA Garot daerah layanan Kota Sigli.

Tabel 13 Link ID eksisting IPA Garot Layanan Kota

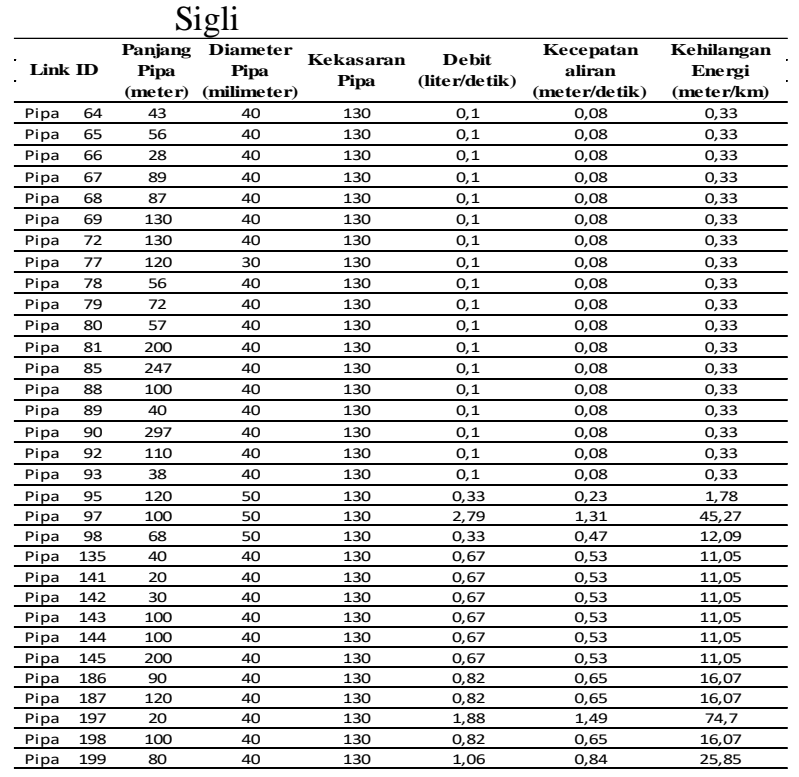

Hasil dari Node ID yang merupakan junction meliputi energi (meter) dan tekanan (meter) yang mengaliri zona prioritas dapat dilihat pada Tabel 14
Tabel 14 Node ID eksisting IPA Garot Layanan Kota \begin{tabular}{ccccc} 
Sigli & & & \\
\hline NODE ID & $\begin{array}{c}\text { Elevasi } \\
\text { (meter) }\end{array}$ & $\begin{array}{c}\text { Kebutuhan } \\
\text { (liter/detik) }\end{array}$ & $\begin{array}{c}\text { Energi } \\
\text { (meter) }\end{array}$ & $\begin{array}{c}\text { Tekanan } \\
\text { (meter) }\end{array}$ \\
\hline
\end{tabular}

\begin{tabular}{|c|c|c|c|c|c|}
\hline \multicolumn{2}{|c|}{ NODE ID } & \multirow{2}{*}{$\frac{\text { (meter) }}{14}$} & \multirow{2}{*}{$\frac{\text { (liter/detik) }}{0,1}$} & \multirow{2}{*}{$\begin{array}{c}\text { (meter) } \\
-39,89\end{array}$} & \multirow{2}{*}{$\begin{array}{c}\text { (meter) } \\
-53,89\end{array}$} \\
\hline Junctions & 73 & & & & \\
\hline Junctions & 75 & 14 & 0,1 & $-39,92$ & $-53,92$ \\
\hline Junctions & 77 & 15 & 0,1 & $-39,96$ & $-54,96$ \\
\hline Junctions & 80 & 14 & 0,1 & $-39,96$ & $-53,96$ \\
\hline Junctions & 81 & 14 & 0,1 & $-39,94$ & $-53,94$ \\
\hline Junctions & 83 & 14 & 0,1 & $-39,97$ & $-53,87$ \\
\hline Junctions & 85 & 14 & 0,1 & $-40,03$ & $-54,03$ \\
\hline Junctions & 87 & 14 & 0,1 & $-39,74$ & $-53,57$ \\
\hline Junctions & 88 & 15 & 0,1 & $-39,64$ & $-54,64$ \\
\hline Junctions & 89 & 14 & 0,1 & $-39,68$ & $-53,68$ \\
\hline Junctions & 90 & 15 & 0,1 & $-39,74$ & $-54,74$ \\
\hline Junctions & 91 & 15 & 0,1 & $-39,78$ & $-54,78$ \\
\hline Junctions & 93 & 14 & 0,1 & $-40,07$ & $-54,07$ \\
\hline Junctions & 94 & 13 & 0,1 & $-40,06$ & $-53,06$ \\
\hline Junctions & 97 & 13 & 0,1 & $-40,04$ & $-53,04$ \\
\hline Junctions & 98 & 14 & 0,1 & $-40,12$ & $-54,12$ \\
\hline Junctions & 99 & 13 & 0,1 & $-40,06$ & $-53,06$ \\
\hline Junctions & 101 & 13 & 0,1 & $-40,04$ & $-53,04$ \\
\hline Junctions & 103 & 17 & 0,33 & $-34,86$ & $-51,65$ \\
\hline Junctions & 105 & 18 & 2,46 & $-39,81$ & $-57,81$ \\
\hline Junctions & 106 & 17 & 0,33 & $-35,29$ & $-52,39$ \\
\hline Junctions & 142 & 14 & 0,67 & $-46,92$ & $-70,92$ \\
\hline Junctions & 144 & 14 & 0,67 & $-47,03$ & $-61,03$ \\
\hline Junctions & 145 & 14 & 0,67 & $-44,06$ & $-58,06$ \\
\hline Junctions & 146 & 14 & 0,67 & $-42,47$ & $-56,47$ \\
\hline Junctions & 150 & 14 & 0,67 & $-43,09$ & $-57,09$ \\
\hline Junctions & 151 & 14 & 0,67 & $-43,46$ & $-57,46$ \\
\hline Junctions & 194 & 18 & 0,82 & $-40,93$ & $-58,93$ \\
\hline Junctions & 196 & 19 & 0,82 & $-40,61$ & $-59,61$ \\
\hline Junctions & 206 & 18 & 1,06 & $-62,29$ & $-80,29$ \\
\hline Junctions & 207 & 18 & 0,82 & $-65,39$ & $-83,39$ \\
\hline Junctions & 209 & 18 & 1,06 & $-65,85$ & $-83,85$ \\
\hline
\end{tabular}

Berdasarkan hasil Link ID yang mengaliri zona prioritas kecepatan aliran pada tiap IPA tidak memenuhi kriteria standar pipa distribusi sebesar 0,3 - 4,5 meter/detik. Pada Node ID beberapa junctions tidak memenuhi kriteria tekanan pipa distribusi sebesar 10 80 meter. Berdasarkan simulasi dengan eksisiting pipa RISPAM perlu dilakukan pemodelan update dengan mengganti diameter pipa distribusi untuk memenuhi kriteria standar pipa distribusi.

\subsubsection{Perbandingan Simulasi pemodelan dan update}

Berdasarkan data rekapitulasi pemodelan jaringan air minum ada beberapa Node ID dan Link ID pada tiap IPA yang tidak memenuhi kriteria perencanaan jaringan distribusi, maka dilakukan pemodelan update dengan mengganti dimensi jaringan pipa untuk memenuhi kriteria perencanaan pipa distribusi. Perbadingan Link ID dan Node ID Update dapat dilihat pada Tabel 14 dan 15.

Tabel 15 Perbandingan Link ID pemodelan dan Update IPA Garot layanan Kota Sigli

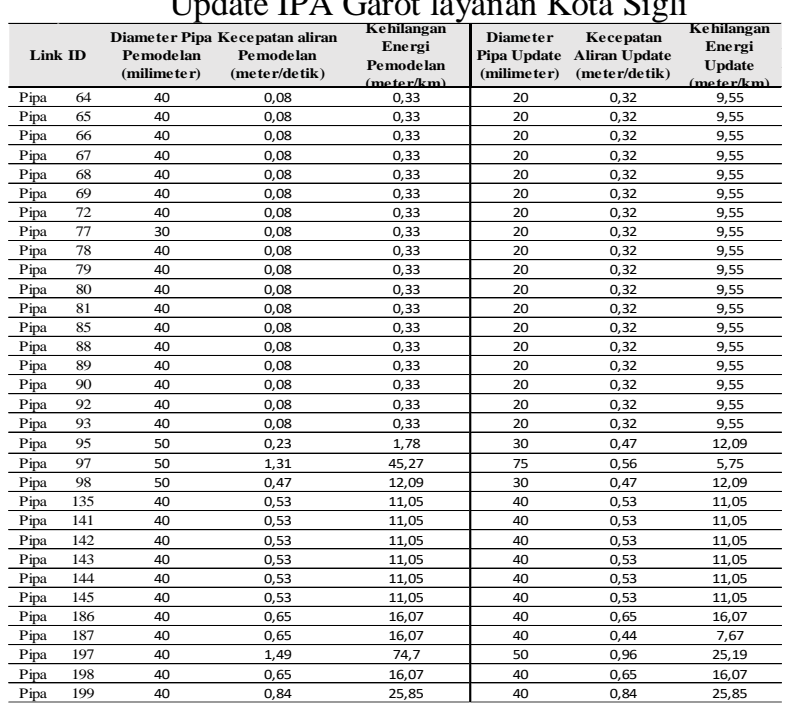


Tabel 16 Perbandingan Node ID pemodelan dan Update IPA Garot layanan Kota Sigli

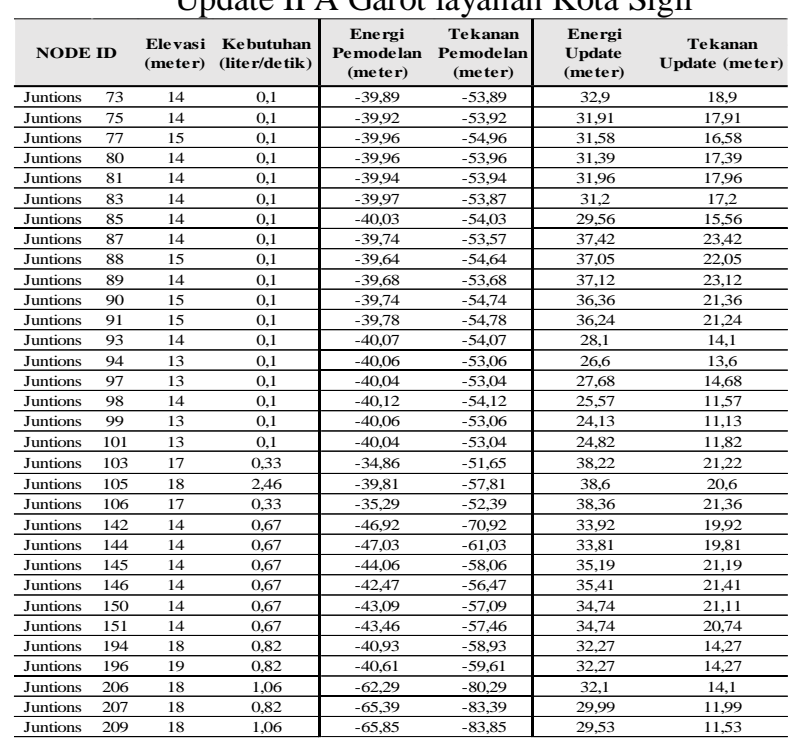

Berdasarkan hasil pada Tabel 15 kecepatan aliran pada tiap link ID IPA Garot sudah memenuhi kriteria standar perencanaan pipa distribusi dan pada Node ID Tabel 16 kriteria tekanan pada update sudah memenuhi kriteria pipa distribusi.

\section{Kesimpulan}

Dari hasil pembahasan dan hasil pada bab sebelumnya diperoleh beberapa kesimpulan sebagai berikut :

1. Kebutuhan jam puncak tertinggi berada pada Kecamatan Pidie sebesar 163,38 liter/detik dan kebutuhan jam puncak terendah ialah Kecamatan Keumala sebesar 27,99 liter/detik.

2. Berdasarkan hasil perhitungan penambahan produksi pada IPA Keumala sebesar 30 liter/detik, penambahan produksi IPA Garot sebesar 70 liter/detik, dan IPA Jabal Ghafur sebesar 130 liter/detik.

3. Berdasarkan hasil simulasi program EPANET perubahan dimensi pipa distribusi pada IPA Keumala sebanyak 69 pipa, IPA Garot sebanyak 65 pipa, dan IPA Jabal Ghafur sebanyak 36 pipa.

\section{Saran}

Berdasarkan hasil penelitian dan pengolahan data dan kesimpulan yang diperoleh maka disarankan sebagai berikut :

1. Perlu adanya upaya dari PDAM Tirta Mon Krueng Baro untuk dapat meningkatkan dalam memenuhi kebutuhan air pada wilayah zona prioritas agar penduduk dapat terlayani seperti yang direncanakan.

2. Perlu adanya pemasangan pompa tambahan pada daerah dengan lokasi terjauh dari pelayanan IPA agar dapat memenuhi tekanan tambahan pada pipa distribusi terjauh.

\section{Daftar Pustaka}

[1]. Peraturan Pemerintah Republik Indonesia, Pengembangan Sistem Penyediaan Air Minum, Jakarta, 2005.

[2]. Bappeda Kabupaten Pidie, Rencana Induk Pengembangan Sistem Penyediaan Air Minum, Bappeda, Kabupaten Pidie, 2014.

[3]. N. Nihayati, Pelanggan PDAM di Pidie Mengeluh Terpaksa Membeli Air Galon, (online), September 2018 (http://aceh.tribunnews.com/2018/11/03/. Pdf, diakses 3 september 2018)

[4]. G. Y. K. Tuames, W. Bunganaen, dan S. Utomo, Perencanaan Teknis Jaringan Perpipaan Air Bersih Dengan Sistem Pengaliran Pompa Di Desa Susulaku Kecamatan Insana Kabupaten Timor Tengah Utara, Jurnal Teknik Sipil Vol. IV, No. 1, April 2015

[5]. A. Wijanarko, Analisis Kebutuhan Dan Ketersediaan Air Bersih Unit Kedawung PDAM Sragen, Tugas Sarjana, Jurusan Teknik Sipil, Universitas Sebelas Maret, 2011

[6]. R. Naway, Pengembangan Sistem Pelayanan Air. Jurnal Tugas Akhir. Universitas Sam Ratulangi. 2013.

[7]. NSPM Kimpraswil, Pedoman dan petunjuk Teknik dan Manual Air Minum Perkotaan, Kimpraswill, Direktorat Jendral Cipta Karya, Jakarta, 2002.

[8]. A. M. Maukari, Perencanaan Teknis Jaringan Air Bersih Di Desa Nunusunu Kecamatan Kualin Kabupaten Timor Tengah Selatan, jurnal Teknik Sipil, Vol. V, No. 1, April 2016

[9]. Direktorat Jenderal Cipta Karya, Buku Panduan Pengembangan Sistem Air Minum, Direktorat jendral Cipta Karya, Jakarta, 2007.

[10]. Badan Standarisasi Nasional, Tata cara Teknik jaringan distribusi dan unit layanan sistem penyediaan air minum, SNI ICT 91.140.60, Jakarta, 2011.

[11]. B. Triatmodjo, Hidraulika II, Beta Offset, Yogyakarta 2008.

[12]. N. Tambun, Perhitungan Debit Andalan Sebagai Sumber Air Bersih Pdam Jayapura, Jurusan Teknik Lingkungan, FTSP-ITS, 2010. 